\title{
Aesthetic Participation for Sustainable Development: A Case Study from Kathmandu, Nepal
}

\author{
Sangeeta $\operatorname{Singh}^{1} \&$ Martina Maria Keitsch ${ }^{2}$ \\ ${ }^{1}$ Institute of Engineering, Tribhuvan University, Lalitpur, Nepal \\ ${ }^{2}$ Faculty of Architecture and Design, Norwegian University of Science and Technology, Trondheim, Norway \\ Correspondence: Sangeeta Singh, Institute of Engineering, Tribhuvan University, Lalitpur, Nepal.
}

Received: June 7, 2018 Accepted: July 30, 2018 Online Published: November 25, 2018

doi:10.5539/jms.v8n4p96 URL: https://doi.org/10.5539/jms.v8n4p96

\begin{abstract}
Art and design are increasingly emphasizing the role of user participation and social inclusion. Some authors claim for example, that art processes should employ creative ideas, abilities and skills of diverse stakeholders. The idea of art as a social sculpture (Beuys) is not new. Art has played an important role for participation of different social groups in common cultural activities for many decades. The role of art, experience and participation in this sense connects Heidegger's interpretation of the artwork, expressed for example, through the significant cultural role of the temple, with modern participatory art and design concepts. The following chapter discusses aesthetic participation as element of an established cultural practice and the role the artwork plays in this practice. Established means here: intrinsic with dynamic potential deliberately changing parts of the practice towards social inclusion. Following the introduction, the second section briefly introduces some current trends on aesthetic participation and continues with an appraisal of Heidegger's ontological aesthetics. Employing insights from section two, the fourth section analyses aesthetic experience and participation within a case study done by the authors: The Akash Bhairab Temple at Indrachowk, Kathmandu Nepal. The fifth section summarizes possibilities and limitations of present concepts and discusses how ontological aesthetics can supplement these. Section six conclusively considers aesthetic participation as contribution to cultural sustainability. The insights of this study might be valuable for artists and educators as well as for stakeholders, who use aesthetic participation as an entry point for social decision-making and inclusion.
\end{abstract}

Keywords: daily practice, aesthetic participation, contemplation, fourfold, social inclusion, cultural sustainability

\section{Introduction}

Aesthetic participation is a valuable approach for understanding, initiating and motivating individual and social development. At the same time, it augments human experiences and reflections on beauty and art. Today aesthetic participation and/or aesthetic engagement is increasingly applied in both artistic, architecture and design projects to include users and other involved parties, and to motivate socio-cultural and sustainability directed activities. Many authors opt for connecting artistic and social activities to co-create and co-design desirable outcomes (Berleant, 2013; Gablik, 2003).

Before discussing values and trends that promote aesthetic participation in the next section, core terms such as aesthetic experience and aesthetic participation will be clarified and their connection discussed. Philosophically, Aristotle's thinking comprises early thoughts on aesthetic experience as "aisthesis" (Greek: "perception"). For him the value of every experience lies in its subjective character; an individual human being evaluates an individual situation. The sensual experience concentrates on a single object (natural or human-made, temples, landscapes, paintings etc.) which can be experienced only by aisthesis. Objects that are considered as special because they stimulate emotions and reactions trigger aesthetic interest. Attention towards an object is in the core of aesthetic experiences, accompanied by positive or negative feelings and (sometimes) thoughts. The intensity of these feelings influences the attitude towards the object-to avoid it or to approach it. For Aristotle the process of aesthetic attention is quite physical, the object activates various senses. Emotionally one experiences enthusiasm or rejection when experiencing aesthetic objects.

In 1750, Aesthetics as an autonomous philosophical discipline, was established through Alexander von 
Baumgarten's “Aesthetica". He distinguishes three aesthetic dimensions: a) Aesthetics as general theory of beauty, b) Aesthetics as philosophy of art and c) Aesthetics as theory of sensual recognition and experiences.

Systematically, three main values of aesthetic experience that trigger aesthetic participation can be indicated (Keitsch 2003): 1) Emotional: The aesthetic makes happy and pleases: This relates to the bodily and sensual experiences of beautiful objects or sceneries. We feel immediate pleasure in sight, touch or smell without the necessity of interpretation. 2) Pragmatic: The aesthetic facilitates the orientation in the environment. The irregularity and diversity of the beautiful things give orientations. As more regulated the environment as more visible and desirable become beautiful things. Beauty functions here as metaphor for the good life and the experience of life-quality. 3) Epistemological: The aesthetic is experienced as a source of judgment, inspiration, imagination and contemplation.

Aesthetic participation can be generally described as any engagement with an aesthetic object (artwork or nature). The historical debate on the relationship between aesthetic experience and participation can be traced back to the 3rd Century to Plotin, who imagined beauty as manifestation of God and His creation and aesthetic participation as partaking of this meta-physical totality. In the 18th Century Idealist philosophers such as Kant promoted secularized contemplative participation as relationship between the aesthetic object and the autonomous subject the beautiful "gives pleasure without interest". Aesthetic participation as meditative (quasi) religious union appeared again in Hegel's idea of the artwork as representation of the world spirit, unembellished of any practical meaning or relevance to the daily life world. As counter reaction to contemplative aesthetics, romanticism and naturalist art evolved in the 19th century. For Naturalist art, especially poetry, the real human being as physical and social entity is the main topic of interest, as single individual, and as group in a socio-cultural context (Keitsch, 2003). In the 20th Century, post-modernists, phenomenologists, critical theorists and pragmatist approaches appeared, the latter, such as Dewey's aesthetics, emphasized the life-worldly, satisfying, didactic and political value of artwork. All 20th century ideas ascribe aesthetic participation as an important role for social and individual development however with different apostrophes.

Three relevant aspects of aesthetic experience for aesthetic participation are:

- Pleasure seeking: Aesthetic experiences relate to consumption, objects have affirmative, ware like attributes.

- Politically focused: an Aesthetics experience is meant to contribute to improve humans, morally or politically, aesthetic education based on socio-political values, or expressed as manifestation of the political status quo is exercised.

- Autonomy generating: Aesthetics experiences of art or natural objects elucidate the alien, unknown (or awesome), show new ways of thinking, and encourage personal freedom (Keitsch, 2013).

Findings from the case study show among others a necessity to consider the dynamics of aesthetic participation that Heidegger's view is lacking.

\section{Literature Review}

Aesthetic participation is an area that facilitates working across disciplinary borders against the backdrop of new challenges of user inclusion in design, architecture, planning and artistic research and practice. Several studies focus e.g. on design for public spaces or participatory place making through cultural platforms (Ermacora et.al 2016, Hamdi, 2009) and / or explore the connections between community involvement, creativity, design and construction (Sanoff, 2000). In terms of values, collaborative activities with the wider public, initiated by artists are regarded not just as generally favourable for influencing socio-cultural processes (Fuad-Luke, 2009) but as liberating per se: "...participation emancipates people by making them active contributors rather than passive recipients. It is therefore a form of design humanism aimed at reducing domination (Bonsiepe, 2006)."

Beauty plays a major role in involving the public and, didactically, mediating new ways of thinking. Aesthetics assumes here an ethical, as well as sustainable connotation (Fry, 2008). The fundamental character of aesthetics, also as counterpart to crude materialistic thinking, is also expressed in Fuad-Luke's almost Hegelian assertion "...beauty that encourages new ideals, values and concept of humankind's 'growth', genuine human flourishing (what the Greeks called 'eudaimonia'), beyond the blinkered thinking of economic growth as 'progress'." Expectations towards the artists all point to a role of facilitating communication about social goals and, in doing so art and design becomes an all-encompassing political activity. Accordingly, Fuad-Luke claims that: “...new physical, institutional, social or other contexts could become the focus of an art work".

The authors above express characteristic views of the current debate, so the following premises may be deduced: 
1) Aesthetic participation presumes that the artist, designer etc. attempts to understand the context and the people he/she is working with, and realizes him/herself as part of the setting.

2) The focus on aesthetic participation is strongly directed towards socio-political impacts.

3) Participation equals actions and many activities are result oriented.

4) The artist, designer etc. adopts a didactic role or function.

The main advantages of current concepts comprise communicative and dynamic aspects of aesthetic exchange e.g. that the professional understands that he/she participates in a social setting which carries its own structure, values and rules and that this participation is time-bound (and ideally this can be mediated to collaborators as well). If this understanding is accompanied by an attempt to integrate different cultures and local approaches, aesthetic participation activities can become a valuable means of communication between different actors in public life. A problematic issue in current aesthetic participation concepts is the deficiency of contemplative aesthetic value; mostly authors are following an all-encompassing activity dogma.

This section discusses Heidegger's aesthetics to examine if his ideas can supplement contemporary concepts regarding both contemplative aspects and understanding of context. Phenomenology was one of the most important philosophical movements in the 20th and 21st century and has had great influence across many applied and professional areas of study: in the humanities, arts, social sciences, architecture and design, but also in public and health sciences. The main objective of Phenomenology is to anchor thinking in the actual experience of things (phenomena) and the life-world. Martin Heidegger (1889-1976) was a student of Edmund Husserl (1859-1938), who developed a phenomenological view of things based on their examination. This examination was not grounded in a scientific or descriptive method (observation, measuring or categorization) but by using a hermeneutic (interpretative) approach. Within this tradition, Heidegger was one of the first thinkers, who developed an aesthetic theory with an explicit foundation in the life-world. Following Husserl, Heidegger argues strongly against a reductionist (scientific) conception of the world, which divides the world into subjects who acknowledge and objects that are acknowledged. In "Being and Time" (1927) he tries to show that the assumed superiority of an objective reality over a reality of daily life practice is in fact an ontological misapprehension, based on a concealed philosophical prejudice. All theory is ultimately based on practice, on an interaction between subject and object and the experience of the world. Heidegger uses the term "world" and "life world" interchangeably in his ontology. Human existence is being-in-the-world (Lindseth \& Norberg, 2004) and the experience of a meaningful world is the condition for the discovery of things as objects. And this implicates that language, art, law and the discursive actions of humans cannot be understood from the position of an objective reality in the meaning of the natural sciences but only from a perspective of the life-world.

Heidegger's aesthetics is closely linked to his ontology. He argues that aesthetics is not just finding pleasure in beautiful objects, or in becoming culturally educated but aesthetic experiences possess a special value for selfand societal development since they allow imagining the interrelatedness of beings in our lifeworld. Heidegger is convinced that any theory of aesthetic experiences, as any theory at all, must derive from a lifeworld, not from an objective world. Using artefacts is one way of aesthetic experiences, which can make aware of truth. The text "The Origin of the Work of Art sets the program": "Art lets truth originate." (p. 77). Truth appears through such different beings as art, language, technology and law. However, truth is not an appearance or an attribute of a phenomenon but represents the potential for things to appear. Every artwork has a twofold connotation represented by the terms "earth" and "world". "World" means the disclosedness of being (the enigmatic) and "earth" the enclosedness of being (the perceptible). By the same time, "world" is not disclosedness per se but signifies a process, which creates clearing as the happening of truth. Truth arises through the aesthetic experience of disclosing and enclosing, representing the dialectics of world and earth. But how can truth become visible in the artwork? Heidegger illustrates this by looking at a Greek temple. The temple is a manifestation of moral, spiritual, social and instrumental interactions for the Ancient Greeks. Simultaneously, the temple exhibits only parts of these experiences, while others are potentially hidden, signifying the oscillation between earth and world. The temple also displays that cultural artefacts are not merely representations or symbols, but they express and generate shared aesthetic cultural, religious etc. experiences. For Heidegger, the artefact thereby manifests a creative condition for the forthcoming of truth.

In "Building, Dwelling, Thinking" (1951), Heidegger introduces the difference between buildings and dwellings, and claims that "dwelling" is more than just inhabiting space but is connected to various experiences. Dwelling requires further to reflect on the question how to live, and thus relates not only to instrumental and practical issues but to also to aesthetic, religious, ethical and social considerations. For Heidegger, humans dwell on earth and under the sky; they remain before the divinities and belong to each other (1975). The unity of these four 
(earth, heaven, the gods and the mortals) calls Heidegger the fourfold (das Geviert). The fourfold has significant meaning for the relation between artefacts/buildings, experiences and human lifestyles: "In saving the earth, in receiving the sky, in awaiting the divinities, in initiating mortals, dwelling occurs as the fourfold preservation of the fourfold. To spare and preserve means, to take under our care, to look after the fourfold in its presenting. What we take under our care must be kept safe." $(1975$, p. 4)

The fourfold is the "mirror game" between heaven and earth, divine and mortal and the happening of truth. Heidegger is not asserting that artworks (or dwellings) allow directly experiencing truth, but that they permit humans to aesthetically experience meaningfulness and feel as been part of it. Heidegger explains this with an example, where again the usefulness and the meaningfulness are conveyed by the artefact: "Let us think for a while of a farmhouse in the Black Forest, which was built some two hundred years ago by the dwelling of peasants. Here the self-sufficiency of the power to let earth and heaven, divinities and mortals enter in simple oneness into things, ordered the house. It placed the farm on the wind-sheltered mountain slope looking south, among the meadows close to the spring. It gave it the wide overhanging shingle roof whose proper slope bears up under the burden of snow, and which, reaching deep down, shields the chambers against the storms of the long winter nights. It did not forget the altar corner behind the community table; it made room in its chamber for the hallowed places of childbed and the 'tree of the dead' for that is what they call a coffin there: the Totenbaumand in this way, is designed for the different generations under one roof the character of their journey through time. A craft which, itself sprung from dwelling, still uses its tools and frames as things, built the farmhouse." $(1975$, p. 8)

Current politically and communally focused aesthetics comprise a pragmatic, almost purpose-mean intention in aiming to realize and or strengthen certain societal values through aesthetic objects and activities. Most of them are goal and/or change oriented but they lack introspective comprehension of and care for the existing lifeworld or, what Heidegger calls "expectation". Expectation connotes that an individual, even if transforming and changing the world, is also able to leave something as it is. Heidegger emphasizes here the etymological meaning of expectation (erwarten), which is in German associated with the word "wait" ("warten" also connected with "aufwarten"- to serve, to take care of). "Expectation" is connoted as openness towards the novel and the alien, which appears out of the unavailable, inaccessible and which cannot be forced. "Expecting" is no passive fatalism, but rather a dynamic, reflective activity, which leaves beings the time to reveal themselves. The virtue connected with this activity is patience as a counterbalance to impulsiveness and actionism.

\section{Method}

The research paradigm for this study is constructivist, the methodology being qualitative. Better understanding of the concepts on aesthetic participation had been based on the literature review. The various concepts focusing on the current views on aesthetic participation explores the aesthetic experience and participation, starting with a brief discussion on current ideas especially following up Heidegger's ontological aesthetics. Heidegger's thoughts have been exemplified using a case study of the Akash Bhairab temple in Indrachowk, Kathmandu. An appraisal of possibilities and limitations of present concepts has been done along with the discussion on how ontological aesthetics can supplement these. Discussion also includes why different types of aesthetic participation for diverse cultural and contextual settings are needed and how aesthetic participation can facilitate cultural sustainability.

\section{Discussion}

Before connecting Heidegger's thoughts with contemporary aesthetic participation concepts, analysis of the elements of aesthetic participation in practice is discussed here, using the Akash Bhairab Temple at Indrachowk, Kathmandu, Nepal, as an example. Tiwari (2006) explains that the traditional public spaces such as Indrachowk provide possibilities to assimilate the heterogeneity of cultural differences. The following section illustrates how aesthetic participation can contribute to foster integration. Historically, Indrachowk was one of the important nodal points of Indo-Tibet trade route from the mid seventh century until the end of 19th century. The square has also significant religious importance with temples like Kantishwor Mahadev, Bansheswor Mahadev, Betal, Ganesha and most importantly Akash Bhairab Temple. 


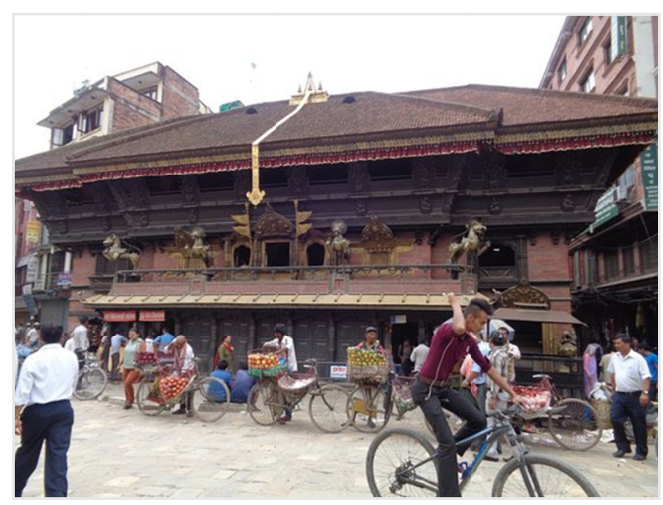

Figure 1. The Akash Bhairab Temple

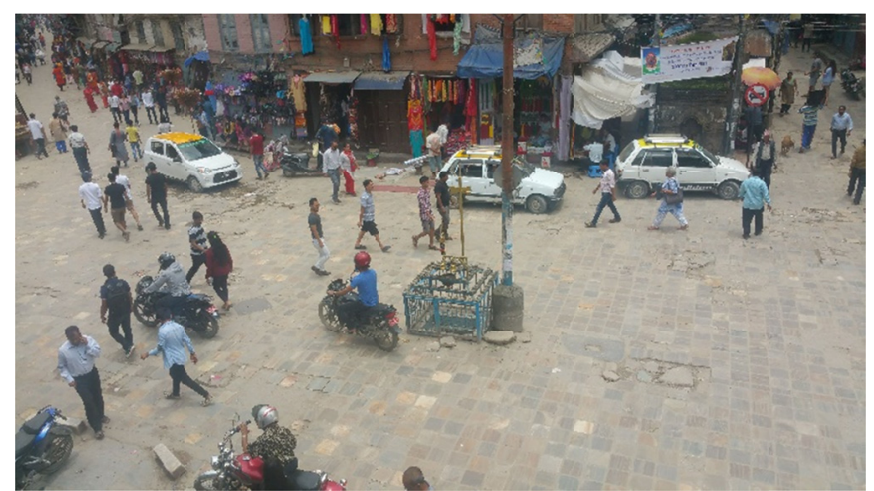

Figure 2. The square in front of the temple

It is the centre of one of the famous chariot festivals of Kathmandu, called Indrajatra. Until the 1980ies Indrachowk and Akash Bhairab Temple were mainly fora for social, religious, spiritual and cultural interactions, while economic activities were limited. In that way, the Akash Bhairab structure resembles Heidegger's example of the Greek temple. And, as in Heidegger's example, the space and the temple were dominated by a homogenous ethnic group, the Newars (Note 1), whose religious beliefs, cultural values and aesthetic practices were inherently tied to Indrachowk. However, from the 1980ies Indrachowk increasingly faced, what Tiwari (2012) calls "wanton commercialization". Some of the micro spaces on the square, which are of social and religious importance, were transforming into all-day plots for business.

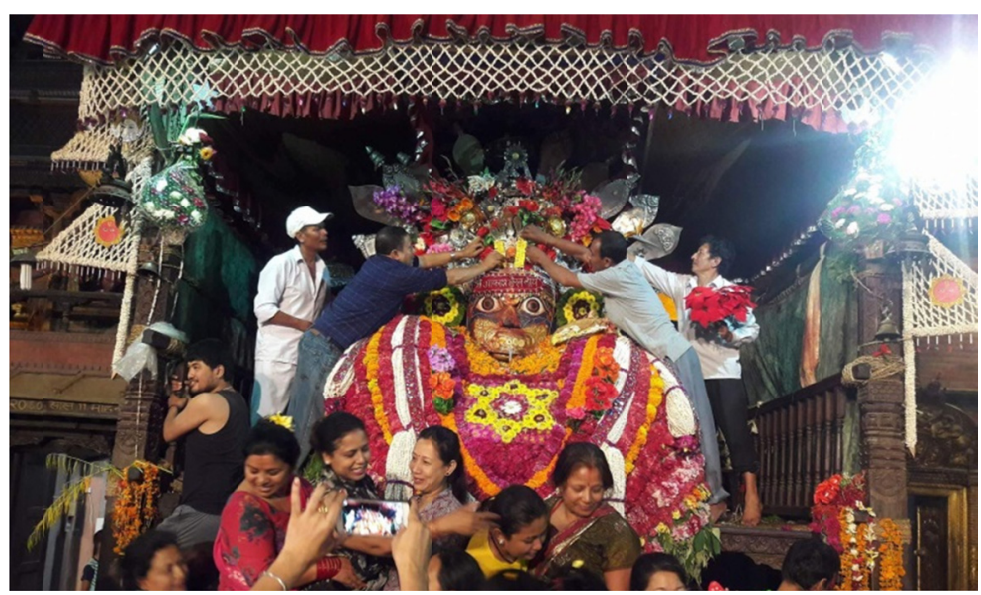

Figure 3. Stage for placing the Akash Bhairab during the Indrajatra festival 
Kathmandu's streets and squares have always been market places as well (Adhikari, 2012). Yet, in Indrachowk, street vendors coming from different parts of country and even from India eventually hindered other activities, and conflicts about how to deal with the issue increased. The Shree Akash Bhairab Indrachowk Club, a local social group in the area, eventually met the problem by imposing a schedule mechanism, where the street market vendors are allowed in the morning till 9:00 AM. The logic behind this mechanism is that most of the consumers buy fresh vegetables and other items in the morning when the traffic congestion is least. Within the square, Akash Bhairab Guthi has claimed a part of space in front of the Akash Bhairab Temple, which is used for various social and religious activities and in a way excludes vendors and other public users. The claim is reinforced during Indrajatra festival, when a stage is prepared within the boundaries for the Akash Bhairab shrine.

Heidegger's example seems to lack the dynamics to deal with changing circumstances and new users. Both the mechanism and the exclusion claim are organizational means to protect and preserve Newars' cultural beliefs and identity embodied in the square and the temple from the growing economic activities. What makes the Indrachowk case particularly interesting is however the strategy of the Akash Bhairab Guthi to include one user group by means of aesthetic and cultural participation. The Marwadi, Indian salesmen, have gained special user rights compared to others. The Marwadi are Hindus and have been at the square for over thirty years with mobile shops selling pashmina shawls. The local Newar groups have managed to integrate them in various social and religious group activities and they donate for feasts and rituals. For example, Marwadi people participate in hymn singing and decoration activities during the Indrajatra festival. From the pashmina shawl shop keepers' view, they have gained access by getting involved in cultural activities organized by the local Newar groups. Creating strong social networks with the Shree Akash Bhairabnath Indrachowk Club and the Guthi has helped them not only to maintain their position but to become accepted as part of the Indrachowk environment.

The brief example of Indrachowk, illustrates that aesthetic participation of diverse users in cultural activities seems to be a promising way to create mutual trust and may lead to sharing access. Within changing social environments, local groups must undergo internal alteration as well to contribute their part to "assimilation". Aesthetic activities can contribute to create a comfortable atmosphere which allows to experience the foreign in a playful and relaxed rather than stressful atmosphere. In case of Indrachowk, cultural and aesthetic activities are an everyday existent starting point for mutual aesthetic collaboration, while participatory aesthetic activities that are initiated by researchers, artists, designers etc. are frequently separated from daily life aesthetic experiences of the participants. This can lead among others to a lack of commitment to continue projects after the initiators have left. A positive side of externally initiated aesthetic participation is that participants learn to apply creative methods to express their ideas, wishes, etc.

The possibilities and limitations of present concepts and how ontological aesthetics can supplement these are discussed here. Concepts on aesthetic participation focus on various aspects and roles of users, the artwork, the artists, designer etc. and society. There is however a common agreement about the importance of aesthetics for societal processes. The possibilities of aesthetic participation for common interactions can be summarized in at least four aspects:

1) Sensual experience: Bodily and sensual sensations and/or aesthetic pleasure. Experience of the body though artworks, buildings, products etc.

2) Emotional, spiritual experience: Art or aesthetic processes as source of transcendental experience, calmness, inspiration for ethics, religion, from senses to empathy.

3) Cultural experience: Heimat, connectedness with environment and culture, art and aesthetics as part of life quality

4) Contemplative experience: Art as the other, as self-purpose, as overwhelming occurrence that transforms one's life.

Several concepts emphasize aspect 1 and 3, either as initiated experience or as life world situation, as articulated programmatically by Berleant: "Art does not consist of objects but of situations in which experiences occur" (1991, p. 49). Most authors are experience focused, a few discuss also the contemplative aspects of experience i.e. aspect 2. They seem to respond to Heidegger's ontological aesthetics represented through the term "expectation". The contemplative aspect appears to be a necessary complement of action oriented aesthetic concepts, and how it can be included in aesthetic participation processes, must be discussed in relation to cultural contexts. Relating to the Indrachowk case, contemplative aesthetic participation will for example relate to prayers, hymns and meditation in the Akash Bhairab temple.

Further, concepts vary on who should initiate participation taking place, while a semi-educational approach is 
prevailing, highlighted e.g. in Thomas et al. (2011): "Becoming familiar with the meanings of participation reflected in aesthetics may help educational policy makers and stakeholders to envision the rich possibilities for education of these tools' collaborative affordances." Moreover, some authors broadcast some sort of "aesthetic politics"- "design is political". Yet, aesthetics as means to transgress the boundaries between individual experience, intersubjective interpretation and communicative action comprise some inadequacies as well. From the authors point of view current concepts of aesthetic participation reveal three main limitations. First, many concepts subscribe to a perfectionist position of aesthetics. This means among others, aesthetic experience gets values of accomplishment and totality, sensibility for experiences becomes adequate to ethical self-realization, and aesthetics become the key to a good Eudaimonia life. Second, accompanied by perfectionism, a fundamentalist character is ascribed, which overstates the significance of aesthetics by transforming it from an element (e.g. of the good life, just communities etc.) to an essential condition (conditio sine qua non). Aesthetic participation and art can certainly widen one's horizon, refine emotions and create engagement but it can neither replace subjective ethical nor communal political decision-making. Yet, democratic debates are the primus motor for a functioning society. For that reason, the aesthetic-expressive dimension of participation must be complemented by an emancipatory-normative dimension and ideally also an empirical-informative dimension of participation. Finally, current Western-centric participatory values such as equality and likeness of participants seem to have limited influence when applied in different cultural and aesthetic settings. In the Indrachowk case, aesthetic access and public participation is e.g. linked to negotiations. Aesthetic participation relates here to understanding of cultural knowledge, values, feelings and beliefs, connected with the space and access is granted by those, who have aesthetic "competence". This competence can be achieved through specific culture related activities and aesthetic participation concepts can provide useful onsets and practices to develop it. Which kinds of methods and tools are useful to encourage communicative aesthetic activities in different cultural settings, is however a topic that is rarely discussed in current concepts and that should be explored more detailed.

\section{Conclusion}

Cultural and social factors determine to a high degree what is appropriate in terms of aesthetics. Therefore it is crucial that a professional understands that he/she participates in a social setting which carries its own structure. For example, working with organic shapes one should analyze what the participants interpret as organic, and what associations they will have about such shapes. In the case of Indrachowk, if a professional introduces novel ways of aesthetic participation to include other groups such as Dalits (Untouchables), she must assure that the process is perceived as socially inclusive by all participants and that is only possible if the Newar culture is respected and taken as an onset for aesthetic exchange. Sometimes, Western-centric participatory values have limited influence when applied in different cultural settings, and a skill of the professional should be adapting aesthetically rather than petrify one's own standards. Methods for aesthetic participation can provide useful onsets to develop contextualized aesthetic practice when applied cautiously. As for aesthetic participation as a contribution for cultural sustainability, it seems to be a way to meet the challenge to mediate between peoples' activities. Wessels (2006) states that culture has its own merits to sustainability. Cultural sustainability looks at ways to improve life-quality and leave a viable inheritance for future generations. This requires not only the recognition of local cultural values, equal rights and providing support for community-based but also action towards participatory approaches. Applying aesthetic participation is one possibility to improve cultural and social interactions.

Concluding with Heidegger, aesthetic participation can be interpreted as essentially hermeneutic practice wherein the designer moves between culture and people to understand their needs and to respond to those through art. According to Adorno, aesthetics allow "non identical" to occur and allow for possibilities to alter lifestyles, simultaneously providing a playful way to try out new views for both the initiator and the participants. Thus, from the authors point of view, aesthetic participation should not become too goal-oriented or politically instrumental, but always leave a way for the other to appear e.g. as "aesthetics of failure" as the following fable explains: "Alas!, said the mouse, "the world is growing smaller every day. At first, it was so big that I was afraid, I ran on and I was glad when at last I saw the walls to the left and right of me in the distance, but these walls are closing in on each other so fast, that I have already reached the end room, and there in the corner stands the trap that I am heading for.' 'You only have to change direction,' said the cat, and ate it up".

\section{References}

Berleant, A. (1991). Art and Engagement. Philadelphia: Temple University Press.

Berleant, A. (2013). What is Aesthetic Engagement? Contemporary Aesthetics, 11.

Beuys' Concept of Social Sculpture and Relational Art Practices Today. Retrieved from 
http://chicagoartmagazine.com/2010/11/beuys\%E2\%80\%99-concept-of-social-sculpture-and-relational-artpractices-today/

Bonsiepe, G. (1997). Design - the blind spot of theory, or, theory - the blind spot of design. Conference paper for a semi-public event at the Jan van Eyk Academy, Maastricht, April 1997.

Bonsiepe, G. (2006). Design and democracy. Design Issues, 22(2), 27-34. https://doi.org/10.1162/desi.2006.22.2.27

Davis, F. (1973). The Martian and the convert. Urban Life and Culture, 2(3), 333-343. https://doi.org/10.1177/089124167300200305

Diaconu, M. (2013). Grasping the Wind? Aesthetic Participation, between Cognition and Immersion. Retrieved from http://digitalcommons.risd.edu/liberalarts_contempaesthetics/vol11/iss1/6/

Ermacora, T., \& Bullivant, L. (2016). Recoded City - Co-Creating Urban Futures. London: Routledge. https://doi.org/10.4324/9781315744209

Forrester, J. (1980). Critical Theory and Planning Practice. Journal of the American Planning Association, 46(3). https://doi.org/10.1080/01944368008977043

Fry, T. (2008). Design Futuring: Sustainability, Ethics and New Practice. Oxford: Berg Publishers.

Fuad-Luke, A. (2009). Design Activism. London: Earthscan.

Gablik, S. (2003). Citizen Designer: Perspectives on Design Responsibility. In S. Heller \& V. Vienne (Eds.). New York: All-worth Press.

Gehlen, A. (1940). Der Mensch. Seine Natur und seine Stellung in der Welt Kap. 8, Das Entlastungsgesetz.

Hamdi, N. (2010). A place maker's guide to building. London: Earthscan. https://doi.org/10.4324/9781849775175

Hussain, S., \& Keitsch, M. (2010). Cultural semiotics, quality, and user perceptions in product development. In S. Vihma (Ed.), Design Semiotics in Use. Helsinki, Aalto University School of Art and Design Publication Series.

Kafka, F. (1973). A Little Fable. In Kafka, Shorter Works (Vol. I). trans. by Malcolm Pasley. London.

Kant, I. (2017). Critique of Judgement $\S$ 5. Retrieved from http://oll.libertyfund.org/titles/kant-the-critique-of-judgement

Keitsch, M. (2003). Naturästhetik und ökologische Ethik, Eine Einführung, Bioethiana, Forschungsergebnisse zur Philosophie, Hamburg 2003, Verlag Dr. Kovacs.

Keitsch, M. (2013). Lecture Adorno: The whole is the untrue, 18 April 2013, Oslo School of Architecture and Design.

Sanoff, H. (2000). Community Participation Methods in Design \& Planning. London: Wiley.

Thomas, R., Whybrow, K., \& Scharbera, C. (2011). A Conceptual Exploration of Participation. Section III: Utilitarian Perspectives and Conclusion. Educational Philosophy and Theory, 44(8). https://doi.org/10.1111/j.1469-5812.2010.00740.x

Tiwari, S. R. (2006). Transforming cultural heritage into sustainable future: A Case study of Patan, Nepal. In M. Nadarajah \& A. T. Yamamoto (Eds.), Urban crisis: culture and the sustainability of cities. United Nations Uni-versity Press.

Wessels, T. (2006). The Myth of Progress: Toward a Sustainable Future. Hanover: University of Vermont Press.

\section{Note}

Note 1. Newar is a homogeneous community of several former ethnic groups, formed through centuries with a com-mon Tibeto-Burmese language and other traditions. They can be both Hindu and Buddhist, divided into different castes (jaat) based on hereditary occupation, marriage circles and ceremonial purity and must follow specific rules based on the social practices. Each Newari is associated with a Guthi - the institutionalized body to man-age, operate and maintain secular and religious artifacts and activities with the hidden interest of preserving the norms and values of community (Tiwari, 2006). 


\section{Copyrights}

Copyright for this article is retained by the author(s), with first publication rights granted to the journal.

This is an open-access article distributed under the terms and conditions of the Creative Commons Attribution license (http://creativecommons.org/licenses/by/4.0/). 